\title{
The kallikrein 14 gene is down-regulated by androgen receptor signalling and harbours genetic variation that is associated with prostate tumour aggressiveness
}

\author{
Felicity Lose ${ }^{1,2, a}$, Mitchell G. Lawrence ${ }^{2, a, b}$, \\ Srilakshmi Srinivasan ${ }^{2}$, Tracy O'Mara ${ }^{1,2}$, Louise \\ Marquart $^{3}$, Suzanne Chambers ${ }^{4-6}$, Robert A. \\ Gardiner $^{6}$, Joanne F. Aitken ${ }^{4,5}$, Amanda B. Spurdle ${ }^{1}$, \\ Jyotsna Batra ${ }^{1,2}$, Judith A. Clements ${ }^{2, *}$ and the \\ Australian Prostate Cancer BioResource ${ }^{2}$ \\ ${ }^{1}$ Molecular Cancer Epidemiology Group, Genetics and \\ Population Health Division, Queensland Institute of Medical \\ Research, 300 Herston Road, Herston, Brisbane, QLD 4006, \\ Australia \\ ${ }^{2}$ Australian Prostate Cancer Research Centre-Queensland, \\ Institute of Health and Biomedical Innovation, Queensland \\ University of Technology, Kelvin Grove, Brisbane, QLD \\ 4059, Australia \\ ${ }^{3}$ Statistics Unit, Queensland Institute of Medical Research, \\ 300 Herston Road, Herston, Brisbane, QLD 4006, Australia \\ ${ }^{4}$ Griffith Health Institute, Griffith University, Southport, \\ Brisbane, QLD 4222, Australia \\ ${ }^{5}$ Viertel Centre for Cancer Research, Cancer Council \\ Queensland, Fortitude Valley, Brisbane, QLD 4004, \\ Australia \\ ${ }^{6}$ University of Queensland Centre for Clinical Research, \\ Royal Brisbane Hospital, Herston, Brisbane, QLD 4029, \\ Australia \\ *Corresponding author
e-mail: j.clements@qut.edu.au
}

\begin{abstract}
Kallikrein 14 (KLK14) has been proposed as a useful prognostic marker in prostate cancer, with expression reported to be associated with tumour characteristics such as higher stage and Gleason score. KLK14 tumour expression has also shown the potential to predict prostate cancer patients at risk of disease recurrence after radical prostatectomy. The KLKs are a remarkably hormone-responsive family of genes, although detailed studies of androgen regulation of KLK14 in prostate cancer have not been undertaken to date. Using in vitro studies, we have demonstrated that unlike many other prostatic $K L K$ genes that are strictly androgen responsive, KLK14 is more broadly expressed and inversely androgen regulated in prostate cancer cells. Given these results and evidence that KLK14 may play a role in prostate cancer prognosis, we also
\end{abstract}

${ }^{a}$ These authors contributed equally to this study.

bPresent address: Department of Anatomy and Developmental Biology, Monash University, Clayton, VIC 3800, Australia. investigated whether common genetic variants in the KLK14 locus are associated with risk and/or aggressiveness of prostate cancer in approximately 1200 prostate cancer cases and 1300 male controls. Of 41 single nucleotide polymorphisms assessed, three were associated with higher Gleason score ( $\geq 7)$ : rs17728459 and rs4802765, both located upstream of $K L K 14$, and rs35287116, which encodes a p.Gln33Arg substitution in the KLK14 signal peptide region. Our findings provide further support for KLK14 as a marker of prognosis in prostate cancer.

Keywords: androgen regulation; Gleason score; kallikreins; KLK14; prostate cancer; single nucleotide polymorphisms (SNPs).

\section{Introduction}

The kallikrein (KLK) family of serine peptidases are a prominent group of prostatic proteins. In the normal prostate, KLKs are secreted into seminal plasma where they act in an enzyme cascade to degrade the seminal clot (Veveris-Lowe et al., 2007; Emami and Diamandis, 2008). In prostate cancer, KLKs are over-expressed and aberrantly secreted into the tumour microenvironment and, ultimately, the bloodstream. This makes the KLKs not only potential functional mediators of tumour progression but also a rich source of biomarkers.

Like several other KLKs, KLK14 has been shown to be aberrantly expressed in hormone-dependent cancers of the breast, ovary and prostate and has been proposed as a useful prognostic marker (Mavridis and Scorilas, 2010). There is some evidence to support a role for KLK14 in prostate cancer risk and aggressiveness. KLK14 was found to be over-expressed in prostate tumours vs. matched normal tissue (Yousef et al., 2003b). Although Rabien et al. (2008) reported that KLK14 mRNA and protein were not differentially expressed between prostate cancer and normal tissue, this same study showed that KLK14 tumour protein expression was associated with tumour pathological characteristics such as higher stage and higher Gleason score, and had potential to predict prostate cancer patients at risk of disease recurrence [as defined by prostate-specific antigen (PSA) relapse] after radical prostatectomy. KLK14 tumour protein expression was also reported to be associated with higher Gleason score by Yousef et al. (2003b), and KLK14 has been shown to be elevated in serum from prostate cancer patients when compared with healthy males (Borgono et al., 2007). Given the recognition that genetic variation can be associated with altered protein expression and prostate cancer risk, as exemplified by 
the discovery that a single nucleotide polymorphism (SNP) in $K L K 3$ is associated with PSA levels and prostate cancer risk (Eeles et al., 2008; Kote-Jarai et al., 2011; Parikh et al., 2011), altogether these results indicate a need to further investigate $K L K 14$, and the SNPs within this gene, as a potential prostate cancer biomarker.

Androgens are critically involved in prostate cancer progression, with androgen deprivation therapy being a key therapeutic regimen for advanced disease. The KLKs are a remarkably hormone-responsive family of genes, especially $K L K 2$ and $K L K 3$, which are considered to be prototypical androgen-regulated genes (Lawrence et al., 2010), and are only expressed in androgen-responsive prostate epithelial cells. Several studies have shown that KLK14 mRNA expression in breast and ovarian cancer cell lines is stimulated by steroid hormones, including androgens, oestrogens, and progestins, although these effects are more subtle at the protein level (Borgono et al., 2003; Yousef et al., 2003a; Paliouras and Diamandis, 2007, 2008b; Shaw and Diamandis, 2008). In prostate cancer cells, KLK14 is ubiquitously expressed at low levels, and is not correlated with the androgen receptor (AR) status of cell lines (Lawrence et al., 2010); however, detailed studies of androgen regulation of KLK14 have not been undertaken to date. In this study, we aimed to examine androgen regulation of KLK14 expression in prostate cancer cells with a goal of better understanding the reported association with prostate cancer progression (Yousef et al., 2003b; Rabien et al., 2008).

In parallel, we investigated the concept that common genetic variation (SNPs) in the KLK14 gene may affect KLK14 expression and hence alter prostate cancer risk and/or the likelihood of more aggressive prostate tumours in carriers by assessing 41 KLK14 gene region SNPs $( \pm 10 \mathrm{~kb})$ in our large prostate cancer case series and male controls.

\section{Results}

We have previously shown that $K L K 14$ mRNA is widely expressed in prostate cell lines, unlike $K L K 2$ and $K L K 3$, which are only expressed in androgen-responsive cells (Lawrence et al., 2010). Using Western blots, we observed that KLK14 protein (Figure 1) has the same expression profile. KLK14 is expressed not only in LNCaP, 22Rv1 and MDA-PCa-2b cells, which are all androgen responsive, but also in $\mathrm{PC} 3$ and DU145 cells, albeit at lower levels, which lack the AR.

The broad expression profile of KLK14 implies that it does not depend on AR signalling. To confirm this observation, increasing concentrations of the synthetic androgen R1881 were added to LNCaP cells, a model of androgendependent prostate cancer that resembles our patient cohort. Surprisingly, KLK14 mRNA expression was significantly down-regulated by treatment with 1 and $10 \mathrm{~nm}$ R1881 (Figure 2A). A time course of R1881 treatment showed that KLK14 mRNA was significantly down-regulated at $24 \mathrm{~h}$ (Figure 2B); however, the decrease in KLK14 protein was not apparent until 7 days of R1881 treatment (Figure 2C). To confirm these changes, we investigated whether decreasing AR activity has

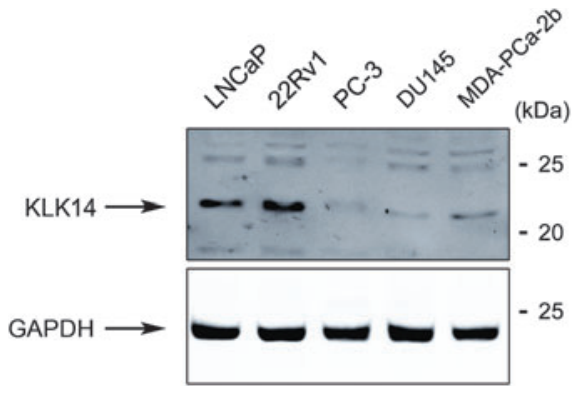

Figure 1 KLK14 is ubiquitously expressed in prostate cancer cells.

Western blots of KLK14 expression in LNCaP, 22Rv1, PC-3, DU145 and MDA-PCa-2b prostate cell lines. KLK14 was detected as an approximately $22-\mathrm{kDa}$ band. GAPDH was used as a loading control. Representative data from two experiments are shown.

the opposite effect on KLKI4 expression. LNCaP cells were deprived of hormones by being cultured in medium containing charcoal-stripped serum (CSS). After 4 days, there was an increase in both KLK14 mRNA (Figure 2D) and protein (Figure 2E) levels. As expected, there was also a decrease in AR protein in hormone-deprived LNCaP cells (Figure 2E). When AR activity was blocked pharmacologically, using the AR antagonist bicalutamide, KLK14 expression was restored compared with R1881 treatment alone (Figure 2F). Furthermore, KLK14 expression was actually stimulated with $100 \mu \mathrm{m}$ bicalutamide. These changes are specific to AR activity because siRNA knockdown of the AR also rescues $K L K 14$ expression (Figure 2G). These observations show that KLK14 is moderately, but significantly, down-regulated by AR signalling, and is therefore differentially regulated compared with other prostatic KLKs.

Given that KLK14 is consistently expressed in prostate cancer cells and significantly upregulated in a hormonedeprived milieu (CSS) or on anti-androgen treatment (bicalutamide), and may play a role in prognosis, we investigated whether SNPs within the KLK14 gene are associated with the occurrence and aggressiveness of prostate cancer. Six SNPs were found to be non-polymorphic in our sample group (Table 1). Results of analyses of the remaining 35 KLK14 SNPs and risk of prostate cancer are displayed in Table 2. No KLK14 SNPs were statistically significantly associated with prostate cancer risk or tumour aggressiveness after Bonferroni correction $(p \leq 0.0014)$. SNP rs66613646 was associated with a modest increased risk of prostate cancer at the $p \leq 0.05$ level [odds ratio (OR) 1.19, 95\% confidence interval (CI) $\left.1.03-1.38, p_{\text {trend }}=0.022\right]$; however, there was no association with risk for tagSNP rs867192 (OR 1.05, 95\% CI 0.91-1.22, $p_{\text {trend }}=0.521$; Table 1), found by analysis of our control dataset to be in high linkage disequilibrium (LD) with rs66613646 $\left(\mathrm{r}^{2}=0.79\right.$; data not shown $)$.

In relation to the possible role of KLK14 SNPs in tumour aggressiveness, three SNPs displayed $p$-values of $\leq 0.05$ when Gleason scores $<7$ were compared with $\geq 7$ (Table 3). Rs 17728459 located approximately $9 \mathrm{~kb}$ upstream of KLK14 was associated with a protective effect, with an OR of 0.33 (95\% CI $\left.0.15-0.73, p_{\text {trend }}=0.006\right)$. A similar result was also 

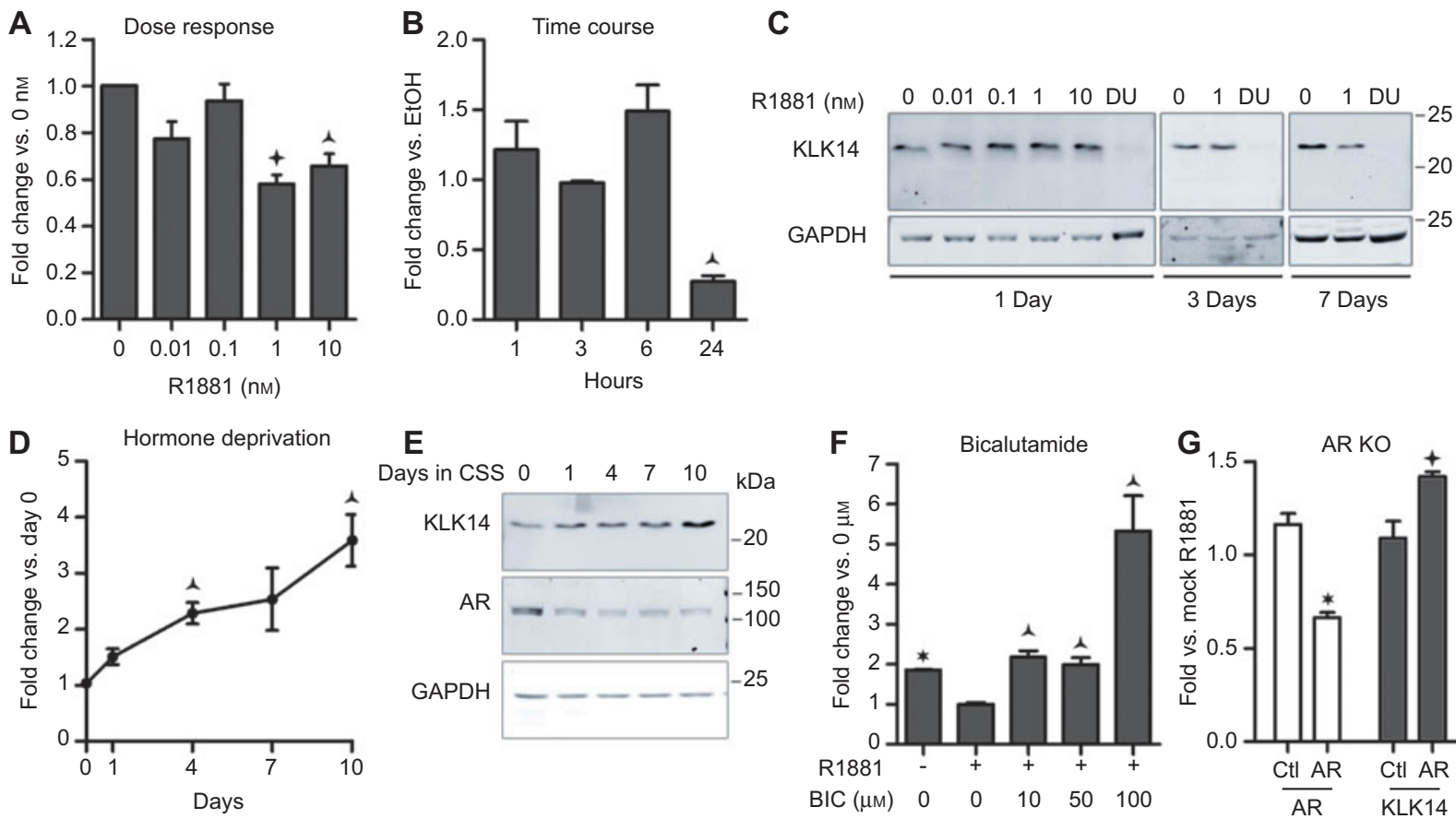

E
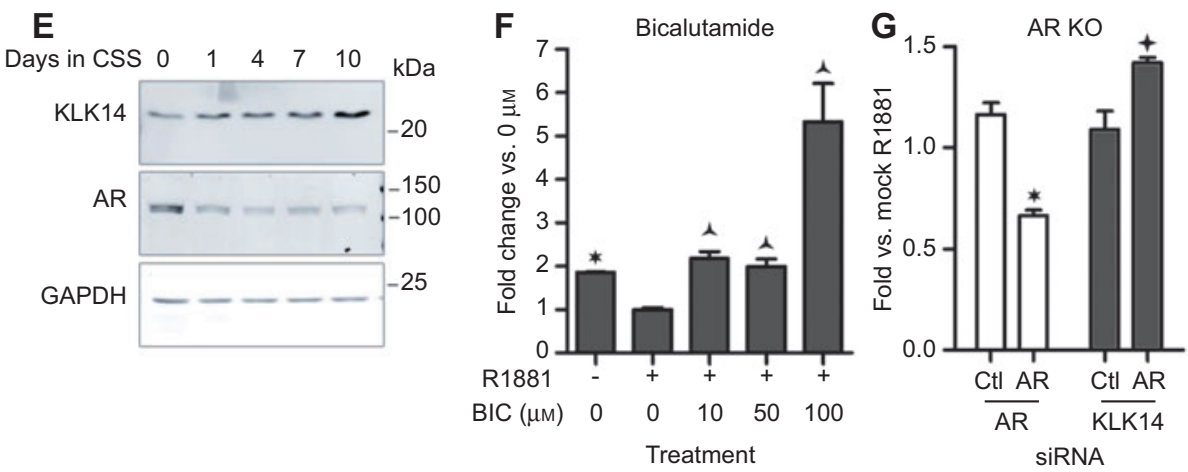

Figure 2 KLK14 is down-regulated by androgens.

(A) KLK14 expression in LNCaP cells treated with 0-10 nм R1881 for $24 \mathrm{~h}$. Data are from qPCR analysis and expressed as average fold changes vs. the ethanol control ( $\mathrm{n}=3$, asterisks indicate significant difference in the fold change relative to 0 nM). (B) Relative KLK14 expression in LNCaP cells treated with $1 \mathrm{~nm} \mathrm{R} 1881$ for up to $24 \mathrm{~h}$ as measured using qPCR. Data represent average fold changes vs. the corresponding ethanol control for each time point ( $\mathrm{n}=2$, asterisks indicate significant differences between $\mathrm{R} 1881$ and the control at each time point). (C) Western blots of KLK14 protein expression in LNCaP cells treated with 0-10 nM R1881 for 1 day or 1 nM R1181 for 3 and 7 days. DU145 cells (DU), which express lower levels of KLK14, were used as control. GAPDH was used to confirm equal protein loading. Representative data from two (7 days) or three ( 1 and 3 days) separate experiments are shown. (D) qPCR data of KLK14 expression in LNCaP cells cultured in medium with CSS for up to 10 days. Results represent average fold changes compared with day 0 ( $\mathrm{n}=3$, asterisks indicate significant difference in fold change relative to day 0). (E) Western blots of KLK14 and GAPDH expression in hormone-deprived LNCaP cells. Representative data from two independent experiments are shown. (F) KLK14 expression in LNCaP cells treated with $1 \mathrm{~nm}$ R1881 and 0-100 $\mu \mathrm{m}$ bicalutamide (BIC). Relative fold changes vs. R1881 alone were measured using qPCR $(n=3$, asterisks indicate significant difference in fold change relative to R1881 alone). LNCaP cells treated with and without 1 nM R1881 were also compared. (G) QPCR data of AR (white bars) and KLK14 (grey bars) expression in LNCaP cells transfected with control or AR-specific siRNA and treated for $48 \mathrm{~h}$ with $1 \mathrm{~nm}$ R1881. Data are normalised to the mock transfection control ( $\mathrm{n}=3$, general linear model, asterisks indicate significant difference between control and AR-specific siRNA). For all experiments, $\boldsymbol{\Lambda} p<0.05, \uparrow p<0.01, * p<0.001$.

seen when 'extreme' Gleason scores were compared $(\leq 6$ vs. $\geq 8$, Table 4), although sample numbers were substantially decreased and the CI overlapped unity. Rs4802765, located around $2 \mathrm{~kb}$ upstream of $K L K 14$, displayed a borderline

Table 1 Rs IDs found to be very rare or non-polymorphic in this study.

\begin{tabular}{lcccc}
\hline Rs ID & Ref. allele & Controls (n) & Cases (n) & $\begin{array}{c}\text { Samples } \\
\text { detected (n) }\end{array}$ \\
\hline rs1880416 & C & 1213 & 1228 & 0 \\
rs73596505 & C & 1266 & 1236 & 0 \\
rs73596515 & G & 1272 & 1229 & 0 \\
rs2569494 & G & 1215 & 1228 & 1 \\
rs2569495 & T & 1215 & 1228 & 0 \\
rs2691268 & G & 1272 & 1229 & 0 \\
\hline
\end{tabular}

ID, identifier; Ref., reference; n, number. association with increased risk of tumour aggressiveness (OR $1.31,95 \%$ CI $1.00-1.72, p_{\text {trend }}=0.050$ ); however, this effect was not reflected in the Gleason score $\leq 6$ vs. $\geq 8$ analysis, despite the high minor allele frequency of 0.33 . Rs35287116 displayed an association with increased tumour aggressiveness (OR 1.28, 95\% CI 1.06-1.56, $p_{\text {trend }}=0.012$ ), which was similarly reflected when analyses were restricted to Gleason score $\leq 6$ vs. $\geq 8$ (Table 4; OR 1.38, 95\% CI 1.03-1.85, $\left.p_{\text {trend }}=0.030\right)$. Studies in our control set revealed rs35287116, encoding a glutamine to arginine amino acid substitution at position 33 in the signal peptide region of KLK14 (Clements et al., 2004), was correlated with $\mathrm{rs} 10500304\left(\mathrm{r}^{2}=0.87\right)$, and this SNP showed comparable, although not significant, results (OR 1.18, 95\% CI 0.95-1.46, $\left.p_{\text {trend }}=0.130\right)$. In addition, SNP rs73051038 exhibited an association with increased tumour aggressiveness only when analyses were restricted to 'extreme' Gleason scores, with OR for Gleason score $\leq 6$ vs. $\geq 8$ of 1.94 (95\% CI $\left.1.10-3.40, p_{\text {trend }}=0.021\right)$, in the same 
Table 2 Association of KLK14 SNPs and prostate cancer risk.

\begin{tabular}{|c|c|c|c|c|c|c|}
\hline$K L K 14 \mathrm{SNP}$ & Ref. allele & Alt. allele & Controls (n) & Cases (n) & OR $(95 \% \mathrm{CI})$ & $p_{\text {trend }}$ \\
\hline rs73596564 & $\mathrm{A}$ & G & 1072 & 1070 & $1.39(0.48-4.02)$ & 0.547 \\
\hline rs17728459 & $\mathrm{C}$ & $\mathrm{T}$ & 1094 & 1087 & $0.91(0.55-1.51)$ & 0.712 \\
\hline rs 73596556 & $\mathrm{C}$ & $\mathrm{T}$ & 1210 & 1224 & $1.83(0.61-5.48)$ & 0.283 \\
\hline rs2691271 & $\mathrm{C}$ & G & 1255 & 1225 & $0.87(0.75-1.01)$ & 0.060 \\
\hline rs 12984853 & $\mathrm{G}$ & $\mathrm{A}$ & 1262 & 1233 & $0.99(0.88-1.11)$ & 0.890 \\
\hline rs 34974522 & G & $\mathrm{A}$ & 1204 & 1210 & $0.93(0.83-1.04)$ & 0.201 \\
\hline rs 2691270 & $\mathrm{~A}$ & $\mathrm{G}$ & 1258 & 1186 & $1.06(0.95-1.19)$ & 0.288 \\
\hline rs2569497 & $\mathrm{T}$ & $\mathrm{C}$ & 1214 & 1225 & $0.93(0.81-1.07)$ & 0.291 \\
\hline rs 34368430 & $\mathrm{G}$ & $\mathrm{A}$ & 1214 & 1227 & $1.10(0.97-1.24)$ & 0.141 \\
\hline rs1880417 & $\mathrm{A}$ & $\mathrm{G}$ & 1272 & 1229 & $2.30(0.21-25.46)$ & 0.496 \\
\hline rs4802765 & $\mathrm{T}$ & $\mathrm{C}$ & 1265 & 1220 & $0.87(0.75-1.02)$ & 0.083 \\
\hline rs7259389 & $\mathrm{C}$ & $\mathrm{T}$ & 1249 & 1171 & $0.98(0.84-1.15)$ & 0.833 \\
\hline rs73596529 & $\mathrm{C}$ & $\mathrm{T}$ & 1212 & 1226 & $0.96(0.82-1.14)$ & 0.665 \\
\hline rs7260199 & $\mathrm{C}$ & $\mathrm{T}$ & 1205 & 1214 & $0.96(0.85-1.08)$ & 0.481 \\
\hline rs12609392 & $\mathrm{G}$ & $\mathrm{A}$ & 1206 & 1212 & $0.99(0.88-1.11)$ & 0.869 \\
\hline rs73051038 & G & $\mathrm{C}$ & 1266 & 1240 & $0.98(0.79-1.22)$ & 0.863 \\
\hline rs2072689 & G & $\mathrm{A}$ & 1309 & 1001 & $1.08(0.96-1.21)$ & 0.199 \\
\hline rs2235100 & $\mathrm{A}$ & G & 1296 & 994 & $1.01(0.87-1.17)$ & 0.934 \\
\hline rs2691244 & $\mathrm{A}$ & $\mathrm{G}$ & 1307 & 997 & $1.10(0.98-1.25)$ & 0.121 \\
\hline rs62114145 & G & A & 1252 & 1184 & $1.06(0.91-1.23)$ & 0.450 \\
\hline rs62114144 & G & $\mathrm{A}$ & 1202 & 1211 & $1.14(0.98-1.33)$ & 0.078 \\
\hline rs 35287116 & $\mathrm{~T}$ & $\mathrm{C}$ & 1264 & 1238 & $1.06(0.94-1.18)$ & 0.354 \\
\hline rs2569491 & $\mathrm{G}$ & $\mathrm{A}$ & 1254 & 1172 & $1.07(0.94-1.21)$ & 0.313 \\
\hline rs2569490 & $\mathrm{C}$ & $\mathrm{T}$ & 1183 & 1193 & $1.43(0.61-3.36)$ & 0.414 \\
\hline rs 10500304 & A & $\mathrm{C}$ & 1296 & 995 & $1.08(0.96-1.22)$ & 0.218 \\
\hline rs10445581 & G & $\mathrm{C}$ & 1315 & 1003 & $1.05(0.92-1.19)$ & 0.495 \\
\hline rs867192 & $\mathrm{C}$ & $\mathrm{A}$ & 1291 & 977 & $1.05(0.91-1.22)$ & 0.521 \\
\hline rs11671942 & $\mathrm{C}$ & $\mathrm{T}$ & 1327 & 1002 & $0.96(0.79-1.16)$ & 0.680 \\
\hline rs11671800 & $\mathrm{C}$ & A & 1326 & 1000 & $1.06(0.91-1.24)$ & 0.441 \\
\hline rs66613646 & G & $\mathbf{T}$ & 1195 & 1194 & $1.19(1.03-1.38)$ & 0.022 \\
\hline rs2569487 & $\mathrm{G}$ & $\mathrm{A}$ & 1252 & 1183 & $0.93(0.82-1.05)$ & 0.251 \\
\hline rs2569485 & $\mathrm{T}$ & $\mathrm{C}$ & 1261 & 1237 & $1.02(0.91-1.14)$ & 0.708 \\
\hline rs7253072 & $\mathrm{C}$ & $\mathrm{T}$ & 1258 & 1185 & $1.06(0.88-1.28)$ & 0.520 \\
\hline rs7253169 & $\mathrm{G}$ & A & 1256 & 1227 & $1.02(0.85-1.22)$ & 0.831 \\
\hline rs2691215 & A & $\mathrm{T}$ & 1071 & 1068 & $0.97(0.86-1.10)$ & 0.632 \\
\hline
\end{tabular}

SNP, single nucleotide polymorphism; Ref., reference; Alt., alternate; n, number; OR, odds ratio; CI, confidence interval.

Bold font indicates SNP displaying a $p$-value $\leq 0.05$.

direction as results for Gleason score $<7$ vs. $\geq 7$ (OR 1.38, 95\% CI 0.91-2.07, $\left.p_{\text {trend }}=0.126\right)$.

\section{Discussion}

Since KLK14 was first cloned in 2001, the prostate has been known to be a prominent site of KLK14 gene expression (Hooper et al., 2001; Yousef et al., 2001). Yet, relatively little is known about the expression profile and transcriptional regulation of $K L K 14$ in the prostate. In this study, we showed that $K L K 14$ is more broadly expressed across androgenresponsive and -insensitive cell lines and is down-regulated by AR signalling.

Considering that prostatic KLKs such as $K L K 2$ and $K L K 3$ are classical AR-activated genes (Lawrence et al., 2010), the observation that androgens suppress KLK14 expression was unexpected. The down-regulation of $K L K 14$ was modest, but consistent, with a $40-75 \%$ decrease depending on the experiment. There was a much more rapid decrease in $K L K 14$ mRNA compared with protein levels. This may be due to the relative instability of KLK14 mRNA, which has a half-life of $<6$ h (M. Lawrence, unpublished observations). Nevertheless, as has also been noted in studies that measured secreted KLK14 levels with ELISAs (Paliouras and Diamandis, 2007, 2008a), changes in KLK14 mRNA and protein levels are correlated. Moreover, the changes we observed are specific because KLK14 levels increase with extended hormone deprivation, bicalutamide treatment and AR knockdown. The modulation, but not complete repression, of KLK14 expression is also consistent with its ubiquitous expression among prostate cancer cell lines. Intriguingly, these results may be tissue specific; previous studies have shown that KLK14 is up-regulated by androgens in a range of breast and ovarian cancer cell lines (Borgono et al., 2003; Yousef et al., 2003a; Paliouras and Diamandis, 2007, 2008b). Therefore, whether KLK14 is activated or repressed by androgens may depend on crosstalk between the AR and other signalling pathways in different cell types. 
Table 3 Association of KLK14 SNPs and prostate tumour aggressiveness (Gleason score $<7$ vs. $\geq 7$ ).

\begin{tabular}{|c|c|c|c|c|}
\hline$K L K 14 \mathrm{SNP}$ & GS < 7 (n) & $\mathrm{GS} \geq 7(\mathrm{n})$ & OR $(95 \% \mathrm{CI})$ & $p_{\text {trend }}$ \\
\hline rs73596564 & 274 & 685 & $2.02(0.22-18.22)$ & 0.533 \\
\hline rs17728459 & 264 & 704 & $0.33(0.15-0.73)$ & 0.006 \\
\hline rs73596556 ${ }^{a}$ & 310 & 785 & - & 1.000 \\
\hline rs2691271 & 316 & 794 & $1.00(0.78-1.28)$ & 0.989 \\
\hline rs12984853 & 312 & 801 & $0.95(0.79-1.15)$ & 0.621 \\
\hline rs34974522 & 301 & 781 & $0.98(0.81-1.19)$ & 0.840 \\
\hline rs2691270 & 300 & 763 & $1.18(0.97-1.43)$ & 0.100 \\
\hline rs2569497 & 310 & 786 & $0.88(0.70-1.11)$ & 0.280 \\
\hline rs34368430 & 310 & 788 & $1.00(0.81-1.23)$ & 0.967 \\
\hline rs1880417 & 319 & 794 & $0.50(0.03-8.06)$ & 0.626 \\
\hline rs4802765 & 314 & 791 & $1.31(1.00-1.72)$ & 0.050 \\
\hline rs7259389 & 294 & 756 & $1.14(0.87-1.50)$ & 0.343 \\
\hline rs73596529 & 310 & 787 & $1.09(0.82-1.46)$ & 0.540 \\
\hline rs7260199 & 302 & 786 & $1.04(0.85-1.28)$ & 0.676 \\
\hline rs12609392 & 300 & 785 & $1.01(0.84-1.22)$ & 0.905 \\
\hline rs73051038 & 313 & 807 & $1.38(0.91-2.07)$ & 0.126 \\
\hline rs2072689 & 259 & 610 & $0.84(0.69-1.03)$ & 0.099 \\
\hline rs2235100 & 258 & 602 & $1.14(0.87-1.49)$ & 0.359 \\
\hline rs2691244 & 259 & 606 & $1.07(0.87-1.33)$ & 0.522 \\
\hline rs62114145 & 300 & 760 & $0.85(0.66-1.09)$ & 0.192 \\
\hline rs62114144 & 301 & 783 & $0.87(0.68-1.11)$ & 0.255 \\
\hline rs35287116 & 312 & 806 & $1.28(1.06-1.56)$ & 0.012 \\
\hline rs2569491 & 295 & 754 & $0.98(0.79-1.21)$ & 0.845 \\
\hline rs $2569490^{\mathrm{a}}$ & 296 & 771 & - & 1.000 \\
\hline rs10500304 & 258 & 603 & $1.18(0.95-1.46)$ & 0.130 \\
\hline rs10445581 & 259 & 611 & $1.16(0.92-1.45)$ & 0.207 \\
\hline rs867192 & 252 & 591 & $1.17(0.90-1.53)$ & 0.249 \\
\hline rs11671942 & 260 & 609 & $1.08(0.76-1.52)$ & 0.676 \\
\hline rs11671800 & 260 & 606 & $1.10(0.84-1.43)$ & 0.509 \\
\hline rs66613646 & 306 & 765 & $1.14(0.89-1.45)$ & 0.302 \\
\hline rs2569487 & 299 & 762 & $0.89(0.72-1.09)$ & 0.265 \\
\hline rs2569485 & 313 & 805 & $1.03(0.85-1.24)$ & 0.768 \\
\hline rs7253072 & 299 & 762 & $0.87(0.64-1.18)$ & 0.368 \\
\hline rs7253169 & 311 & 797 & $1.13(0.83-1.55)$ & 0.437 \\
\hline rs2691215 & 274 & 685 & $1.04(0.85-1.28)$ & 0.716 \\
\hline
\end{tabular}

SNP, single nucleotide polymorphism; GS, Gleason score; n, number; $\mathrm{OR}$, odds ratio; $\mathrm{CI}$, confidence interval.

Bold font indicates SNPs displaying a $p$-value $\leq 0.05$.

${ }^{a} \mathrm{SNP}$ too infrequent in these groups to calculate OR $(95 \% \mathrm{CI})$.

The repressive actions of the AR are well recognised but poorly understood. Studies have noted that slightly fewer genes are repressed by androgens than stimulated (Clegg et al., 2002; Bolton et al., 2007; Prescott et al., 2007). Like $K L K 14$, most of these genes are moderately down-regulated rather than completely repressed (Kojima et al., 2006; Prescott et al., 2007). One potential mechanism is that AR actively inhibits target gene expression by recruiting co-repressor proteins such as NCoR and SMRT. This is unlikely for KLK14 because its expression is rescued by bicalutamide, which maintains the ability of the AR to interact with co-repressor and bind to DNA (Hodgson et al., 2007; Prescott et al., 2007). The AR also down-regulates gene expression without binding to target promoters. It can compete for limited pools of co-activators or form inhibitory interactions with other transcription factors such as NFKB, Sp1, AP-1, cJun and ATF2
Table 4 Association of $K L K 14$ SNPs and prostate tumour aggressiveness (Gleason score $\leq 6$ vs. $\geq 8$ ).

\begin{tabular}{|c|c|c|c|c|}
\hline$K L K 14 \mathrm{SNP}$ & $\mathrm{GS} \leq 6(\mathrm{n})$ & $\mathrm{GS} \geq 8(\mathrm{n})$ & OR $(95 \% \mathrm{CI})$ & $p_{\text {trend }}$ \\
\hline rs73596564 ${ }^{a}$ & 274 & 128 & - & 1.000 \\
\hline rs 17728459 & 264 & 176 & $0.15(0.02-1.15)$ & 0.068 \\
\hline rs73596556 & 310 & 151 & - & \\
\hline rs2691271 & 316 & 158 & $0.88(0.61-1.28)$ & 0.506 \\
\hline rs12984853 & 312 & 160 & $1.05(0.79-1.41)$ & 0.733 \\
\hline rs34974522 & 301 & 151 & $1.06(0.79-1.42)$ & 0.720 \\
\hline rs2691270 & 300 & 162 & $1.14(0.86-1.51)$ & 0.367 \\
\hline rs2569497 & 310 & 151 & $0.85(0.59-1.21)$ & 0.366 \\
\hline rs34368430 & 310 & 152 & $1.10(0.80-1.51)$ & 0.571 \\
\hline rs1880417 & 319 & 158 & - & 1.000 \\
\hline $\mathrm{rs} 4802765^{\mathrm{a}}$ & 314 & 157 & $1.18(0.80-1.74)$ & 0.401 \\
\hline rs7259389 & 294 & 161 & $1.16(0.79-1.72)$ & 0.447 \\
\hline rs73596529 & 310 & 151 & $1.22(0.81-1.83)$ & 0.349 \\
\hline rs7260199 & 302 & 157 & $0.77(0.56-1.05)$ & 0.095 \\
\hline rs12609392 & 300 & 157 & $1.27(0.95-1.68)$ & 0.103 \\
\hline rs73051038 & 313 & 163 & $1.94(1.10-3.40)$ & 0.021 \\
\hline rs2072689 & 259 & 145 & $0.95(0.71-1.27)$ & 0.713 \\
\hline rs2235100 & 258 & 145 & $1.30(0.89-1.88)$ & 0.173 \\
\hline rs2691244 & 259 & 144 & $1.11(0.82-1.51)$ & 0.504 \\
\hline rs62114145 & 300 & 161 & $0.89(0.62-1.29)$ & 0.547 \\
\hline rs62114144 & 301 & 157 & $0.84(0.58-1.22)$ & 0.371 \\
\hline rs35287116 & 312 & 162 & $1.38(1.03-1.85)$ & $\mathbf{0 . 0 3 0}$ \\
\hline rs2569491 & 295 & 162 & $0.96(0.70-1.32)$ & 0.798 \\
\hline rs $2569490^{\mathrm{a}}$ & 296 & 154 & - & 1.000 \\
\hline rs10500304 & 258 & 146 & $1.24(0.91-1.68)$ & 0.169 \\
\hline rs10445581 & 259 & 145 & $1.19(0.86-1.64)$ & 0.294 \\
\hline rs867192 & 252 & 142 & $1.18(0.82-1.72)$ & 0.377 \\
\hline rs11671942 & 260 & 145 & $1.10(0.67-1.81)$ & 0.697 \\
\hline rs11671800 & 260 & 145 & $1.10(0.75-1.61)$ & 0.632 \\
\hline rs66613646 & 306 & 147 & $1.11(0.76-1.61)$ & 0.591 \\
\hline rs2569487 & 299 & 162 & $0.87(0.63-1.19)$ & 0.376 \\
\hline rs2569485 & 313 & 162 & $1.08(0.81-1.44)$ & 0.583 \\
\hline rs7253072 & 299 & 162 & $0.92(0.59-1.45)$ & 0.725 \\
\hline rs7253169 & 311 & 163 & $1.26(0.80-1.98)$ & 0.312 \\
\hline rs2691215 & 274 & 128 & $1.11(0.80-1.53)$ & 0.538 \\
\hline
\end{tabular}

SNP, single nucleotide polymorphism; GS, Gleason score; n, number; OR, odds ratio; CI, confidence interval.

Bold font indicates SNPs displaying a $p$-value 0.05 .

${ }^{a} \mathrm{SNP}$ too infrequent in these groups to calculate OR (95\% CI).

${ }^{b}$ Rare allele was not detected in either group.

(Grosse et al., 2012). Therefore, the KLK14 promoter should be further characterised to help determine the mechanism of AR-mediated repression.

The differential androgen regulation of KLK14 compared with other prostatic KLKs has important implications for their relative expression profiles in prostate cancer. AR-activated genes such as $K L K 2$ and $K L K 3$ are generally down-regulated as the primary tumour de-differentiates and are then further reduced in metastases (Clegg et al., 2002; Bolton et al., 2007; Prescott et al., 2007). In patients that undergo androgen deprivation therapy, AR activated genes are initially down-regulated, but are then re-expressed in castrate-resistant disease (Holzbeierlein et al., 2004). Although KLK3 expression generally follows these trends, it is highly heterogeneous after hormone deprivation therapy as tumours proceed towards 
castration resistance (Mostaghel et al., 2007). This variability may be due to the different ways that prostate cancer cells adapt to castrate androgen levels. Although the effect of hormone ablation on KLK14 expression has not yet been reported, other genes that are repressed by androgens, such as IGFBP 3 and relaxin, are initially up-regulated by hormone deprivation therapy, but then decrease in castrate-resistant prostate cancer (Kojima et al., 2006; Thompson et al., 2006). This suggests that $K L K 3$ and $K L K 14$ may have opposite expression profiles. If this is the case, the ratio of $K L K 3$ to $K L K 14$ expression may be a useful measure of AR activity that overcomes some of the variability between patients. Therefore, further analysis of the relative expression profiles of KLK3, KLK14 and other prostatic KLKs is warranted.

In parallel to our investigation of the androgen regulation of KLK14 expression, we performed a comprehensive investigation of the role of common genetic variations in the KLK14 gene in prostate cancer risk and/or tumour aggressiveness by assessing the majority of KLK14 SNPs that have not been covered by previously performed genome-wide association (GWA) studies. Our study of over 1200 cases and 1300 male controls identified no SNPs to be associated with prostate cancer predisposition, but revealed several KLK14 SNPs to be potentially associated with tumour aggressiveness. To the best of our knowledge, only one other study has specifically examined the role of KLK14 SNPs in prostate cancer aside from genome-wide investigations. Analogous to our findings, the study by Klein et al. (2010) found none of the KLK14 SNPs assessed (including rs2569491, rs35287116, rs7260199, rs7259389 and rs73596529 examined in our study) to be associated with prostate cancer risk in the Cancer Prostate in Sweden (CAPS) 1 sample set of over 1400 cases and 700 controls. The study of Klein et al. did not assess the relation of KLK14 SNPs with tumour aggressiveness.

In our study of approximately 1200 cases, two SNPs upstream of KLK14 were found to be associated with tumour aggressiveness, rs17728459 with decreased aggressiveness and rs4802765 with more aggressive tumours. Neither were located in known or predicted hormone response elements (Sandelin and Wasserman, 2005; Kennedy et al., 2010), although preliminary bioinformatic analysis of the potential effects of rs $4802765 \mathrm{~T}>\mathrm{C}$ on transcription factor binding sites (Grabe, 2000) predicted that the presence of the C allele introduces two Sp1 sites and an NF-1 site. Interestingly, Sp1 regulates the expression of the $A R$ and $K L K 3$ genes, and $\mathrm{Sp} 1$ expression has been found to be elevated in prostate cancer and associated with prognosis (Sankpal et al., 2011). In addition, a GWAS-identified prostate cancer-associated SNP near the NKX3.1 gene (Eeles et al., 2009) has recently been shown to alter the binding of Sp1 (Akamatsu et al., 2010). We also identified SNP rs35287116 in the coding region of KLK14 to be associated with increased tumour aggressiveness. Rs35287116 encodes the non-synonymous substitution p.Gln33Arg in the signal peptide region (Clements et al., 2004), but is not predicted to alter cleavage of the signal peptide by SignalP 3.0 (Bendtsen et al., 2004) or PSORT II (Nakai and Horton, 1999) and is calculated to be tolerated by the bioinformatic algorithms SIFT (Ng and Henikoff, 2001) and PolyPhen-2 (Adzhubei et al., 2010). However, ESEFinder (Smith et al., 2006) predicts that rs35287116 may affect an exonic splicing enhancer site and hence alter splicing of KLK14.

Although the functional role of KLK14 in prostate cancer has not been investigated, the substrates that have been identified in biochemical studies could explain the association between KLK14 SNPs and tumour aggressiveness. KLK14 is normally secreted into seminal plasma (Borgono et al., 2007; Emami et al., 2008), but the breakdown of glandular architecture in prostate cancer likely leads to the accumulation of KLK14 in the tumour microenvironment. KLK14 may directly promote the migration and invasion of tumour cells by activating proteinase activated receptor 2 signalling (Oikonomopoulou et al., 2006; Stefansson et al., 2008; Gratio et al., 2011); degrading extracellular matrix proteins such as fibronectin, laminin and collagen I to IV (Borgono et al., 2007; Rajapakse and Takahashi, 2007); and activating enzyme cascades with KLK1-3, KLK5 and KLK11 (Brattsand et al., 2005; Yoon et al., 2007; Emami and Diamandis, 2010). KLK14 also activates latent transforming growth factor $\beta 1$ (Emami and Diamandis, 2010) and degrades insulin-like growth factor binding proteins 2 and 3 (Borgono et al., 2007), suggesting it affects the growth and differentiation of prostate cancer cells. Ultimately, however, the actions of KLK14 in the tumour microenvironment will also depend on the levels of other proteases that activate it, as well as serpins and metal ions that inhibit KLK14 enzyme activity.

To date, there has been little success in attempts to delineate, and then validate, the contribution of SNPs to prostate tumour aggressiveness (Duggan et al., 2007; Kader et al., 2009; Witte, 2009; Lubahn et al., 2010; Fitzgerald et al., 2011; Lin et al., 2011). There are several possible reasons for this (reviewed in Oon et al., 2011), such as the fact that one prostate can have multiple tumour foci that display different Gleason scores, and it is well known that there is much heterogeneity between tumours that are graded Gleason score 7. We attempted to circumvent some issues involving tumours with Gleason score 7 by restricting analyses to those patients with the more 'extreme' Gleason scores of $\leq 6$ and $\geq 8$. Although this depleted our sample set dramatically, several SNPs remain candidates for further investigation in larger sample sets. Unfortunately, long-term follow-up data were not available for our prostate cancer cases, so we could not investigate the role of KLK14 SNPs in prognosis at this time; however, this will be an important analysis in the future.

In summary, we have demonstrated that unlike other prostate-expressed $K L K$ genes that are strictly androgen responsive, KLK14 is more broadly expressed and inversely androgen regulated, increased by anti-androgens and in an androgen-deprived milieu. This suggests that KLK14 expression is maintained throughout prostate cancer, including the initial stages of hormone deprivation, with subsequent proteolytic effects in the tumour microenvironment that promote tumour progression. In addition, our well-sized study suggests a contribution of SNPs in the KLKI4 gene to the 
development of more aggressive prostate cancer, an interesting finding considering previous reports that KLK14 expression is a possible prognostic factor for tumour characteristics and progression-free survival. Validation of these results in much larger sample sets such as those available from the PRACTICAL prostate cancer consortium would highlight KLK14 SNPs as a possible prognostic marker to identify patients that may benefit from more immediate and proactive treatment of their disease.

\section{Materials and methods}

\section{$K L K 14$ expression and androgen regulatory studies}

Cell culture and androgen treatments $\mathrm{LNCaP}, 22 \mathrm{Rv} 1, \mathrm{PC} 3$, DU145 and MDA-PCa-2b prostate cancer cell lines were acquired from the American Type Culture Collection (Manassas, VA, USA). All cells were grown in RPMI 1640 medium (Invitrogen, Mount Waverly, Australia) with $10 \%$ foetal calf serum (FCS, Invitrogen), 50 $\mathrm{U} / \mathrm{ml}$ penicillin $\mathrm{G}$ and $50 \mu \mathrm{g} / \mathrm{ml}$ streptomycin (Invitrogen), except for MDA-PCa-2b cells, which were cultured in BRFF-HPC1 medium (AthenaES, Baltimore, MD, USA) with $20 \%$ FCS and antibiotics. LNCaP cells were cultured in phenol red-free RPMI 1640 with $10 \%$ CSS for $72 \mathrm{~h}$ before androgen treatments. Cells were then treated with 0.01-10 nм R1881 (Perkin Elmer, Boston, MA, USA) or ethanol vehicle control for $24 \mathrm{~h}$, unless otherwise stated. For hormone deprivation experiments, LNCaP cells were cultured in medium containing CSS for up to 10 days with medium changes after 4 and 7 days. For bicalutamide treatments, cells were pre-treated for $2 \mathrm{~h}$ with 0-100 $\mu \mathrm{M}$ bicalutamide (AstraZeneca, Brisbane, QLD, Australia) and then cultured for a further $24 \mathrm{~h}$ with $1 \mathrm{~nm}$ R1881 and bicalutamide. AR knockdown with siRNA was performed as previously described (Jia et al., 2006, 2008). LNCaP cells were transfected with an AR-specific or scrambled siRNA for $48 \mathrm{~h}$ using Oligofectamine (Invitrogen) and then treated for $48 \mathrm{~h}$ with $1 \mathrm{~nm} \mathrm{R} 1881$.

RNA extractions and quantitative RT-PCR Total RNA was extracted using TRIzol and then treated with DNase I (Invitrogen). SuperScript III reverse transcriptase was used to synthesise cDNA (Invitrogen). Quantitative PCR (qPCR) was performed with ABI PRISM 7000, 7300 and 7900 thermocyclers and SYBR Green PCR Master Mix (Applied Biosystems, Scoresby, Australia). KLK14, $G A P D H$ and $18 S$ primer sequences have previously been reported (Lawrence et al., 2010). The comparative $\mathrm{C}_{\mathrm{T}}\left(\Delta \Delta \mathrm{C}_{\mathrm{T}}\right)$ method was used to calculate relative gene expression compared with control samples. Protein extractions and Western blotting Cells were lysed in buffer containing $10 \mathrm{~mm}$ Tris (pH 8.0), $150 \mathrm{~mm} \mathrm{NaCl}, 5$ mM EDTA, $1 \%$ Triton X-100 and $1 \times$ complete protease inhibitor cocktail (Roche, West End, QLD, Australia), and total protein concentrations were measured using a Bicinchoninic Assay Kit (Pierce, Progen, Darra, QLD, Australia). Forty micrograms of each sample was separated using $14 \%$ sodium dodecyl sulphatepolyacrylamide gels. Membranes were probed with either a rabbit anti-KLK14 catalytic domain antibody [a gift from Preston Alexander, TriplePoint Biologics (Forest Grove, OR), and also available from Abcam, Cambridge, MA, USA] or a rabbit anti-GAPDH antibody (Abcam) diluted in Odyssey buffer (LI-COR Biosciences, Millennium Science, Surrey Hills, NSW, Australia). The blots were then incubated with a goat-anti-rabbit-680 (Invitrogen) fluorescent secondary antibody and imaged using a LI-COR Odyssey scanner. Odyssey software was used to adjust the brightness, contrast and intensity of images.

\section{Analysis of KLK14 SNPs in prostate cancer cases and controls}

Study subjects Study subjects have been described elsewhere (Baade et al., 2010; Lose et al., 2011). Briefly, from 2004 onwards, 1349 histopathologically confirmed prostate cancer cases were recruited through private and public urologists in Queensland, Australia, through three prostate cancer studies or resources: the Retrospective Queensland Study ( $\mathrm{n}=154$; Lai et al., 2007), the Prostate Cancer Supportive Care and Patient Outcomes Project (ProsCan, n=857; Baade et al., 2010) and from the Australian Prostate Cancer BioResource (APCB, n=338; http://www.apccbioresource. org.au/index.html). Men presented to urologists with lower urinary tract symptoms and/or abnormal serum PSA, and $72 \%$ of cases possessed prostate tumours of Gleason score 7 or above. Cases ranged in age at diagnosis from 36 to 88 years (median 63 years). Male controls $(\mathrm{n}=1405)$ with no self-reported personal history of prostate cancer were randomly selected from the Australian Electoral Roll and age-matched (in 5-year groups) and post-code matched to cases $(n=569)$, or recruited through the Australian Red Cross Blood Services in Brisbane $(\mathrm{n}=836)$. Controls were not screened for PSA levels and analyses excluded 38 controls with age at interview $<36$ years (the age of the youngest case); included controls ranged in age at interview from 36 to 89 years of age (median 62 years). All participants had self-reported Caucasian ethnicity and gave written informed consent. The study protocol was approved by the Human Research Ethics Committees of the Queensland University of Technology, Queensland Institute of Medical Research, the Mater Hospital (for Brisbane Private Hospital), the Royal Brisbane Hospital, Princess Alexandra Hospital and the Cancer Council Queensland.

SNP selection and genotyping The KLK14 gene region used for SNP selection was chr19:56262966..56289314 (hg18), which encompasses the KLK14 gene $\pm 10 \mathrm{~kb}$. All SNPs in this region were extracted from National Center for Biotechnology Information (NCBI) dbSNP build 130 (Sherry et al., 2001), CHIP SNPper (Riva and Kohane, 2004) and the 'ParSNPs' database (Goard et al., 2007) and duplicates were removed. SNPs not classified as validated were removed, and validated SNPs were further investigated for occurrence in Caucasians using SPSmart (Amigo et al., 2008) and 1000 Genomes (2010). Additional SNPs excluded from investigation included all SNPs on the Illumina 550K, 610K and Omni1 genomewide genotyping chips and SNPs assessed in the Cancer Genetic Markers of Susceptibility (CGEMS) project (Yeager et al., 2007), unless there was evidence of association with prostate cancer by CGEMS $(p<0.05)$. SNPs in high LD $\left(r^{2} \geq 0.80\right)$ with these excluded Illumina and CGEMS SNPs were also removed, determined by the SNP Annotation and Proxy Search program (SNAP) version 2.1 (Johnson et al., 2008) using HapMap release 22 (1000 Genomes data was not available at the time of initiation of this study). We then prioritised for genotyping all independent SNPs $\left(\mathrm{r}^{2}<0.80\right)$ according to SNAP using HapMap release 22 data $(n=42)$. As part of a previous study, we had also genotyped eight KLK14 tagSNPs (selected using HapMap data release 24/phase II, Nov 2008, NCBI build 36, dbSNP b126, using the Tagger program within Haploview v4.1; Barrett et al., 2005).

SNPs were genotyped using iPLEX Gold assays on the Sequenom MassARRAY platform (Sequenom, San Diego, CA, USA), as described previously (Lose et al., 2010). There were four negative $\left(\mathrm{H}_{2} \mathrm{O}\right)$ controls per 384-well plate, and quality control parameters included genotype call rates $>95 \%$, a combination of cases and controls on each plate, inclusion of 20 duplicate samples per 384-well plate ( $>5 \%$ of samples) with $\geq 98 \%$ concordance between duplicates and Hardy-Weinberg equilibrium $p$-values $>0.05$. Of a total of 50 
KLK14 SNPs selected for investigation, six could not be designed for Sequenom assays, and after application of quality control parameters, 41 SNPs were successfully genotyped.

\section{Statistical methods}

Gene expression data were analysed using Predictive Analytics Software (PASW) Statistics version 17.0.2 (SPSS Inc., Chicago, IL, USA) and GraphPad Prism. The significance of fold changes relative to the reference group was assessed by one-sample $t$-test. Differences of the fold changes between groups were assessed using one-way ANOVA, and when there was evidence of variance heterogeneity the Brown-Forsythe robust test (Brown and Forsythe, 1974) was used. General linear models were used to compare the fold changes relative to mock R1881 between the control and AR siRNA groups (Figure 2G). All error bars represent the standard error of the mean of biological replicates performed on separate occasions. $p$-Values are indicated by $\lambda$ for $p<0.05, \downarrow$ for $p<0.01$, and $*$ for $p<0.001$.

PASW Statistics version 17.0.2 (SPSS Inc.) was used for genetic analyses. Genotype and allele frequencies were calculated for the patient and control groups. Comparisons of allele and genotype distribution and their association with prostate cancer susceptibility and clinical data were analysed under a linear model using logistic regression analysis and all analyses were adjusted for age (as a continuous variable). Prostate cancer cases with tumour Gleason scores $\geq 7$ were classified as aggressive. Analyses were also performed comparing 'extreme' Gleason categories, $\leq 6$ (maximum number of cases $=334$ ) vs. $\geq 8$ (maximum cases $=176$ ).

\section{Acknowledgements}

The authors thank the many patients and control subjects who participated willingly in this study, and the numerous institutions and their staff who have supported the recruitment. The authors are very grateful to staff at the Australian Red Cross Blood Services for their assistance with the collection of risk factor information and blood samples of healthy donor controls; members of the Cancer Council Queensland for ProsCan participant information, including Megan Ferguson and Andrea Kittila; the hospitals that participated in recruitment for the ProsCan study: Greenslopes Private, Royal Brisbane, Mater Adults, Princess Alexandra, Ipswich, QEII, Redlands and Redcliffe Hospitals, Townsville General Hospital and Mackay Base Hospital; Drs. Peter Heathcote, Glenn Wood and Greg Malone for the Australian Prostate Cancer BioResource (APCB) patient recruitment, and Pamela Saunders, Allison Eckert and Dr. Trina Yeadon for APCB project management; Drs. John Yaxley and David Nicol for recruitment of patients into the Retrospective Queensland Study and the Urological Society of Australia and New Zealand. Thank you to the members of the Australian Prostate Cancer Research CentreQueensland at QUT and the QIMR Molecular Cancer Epidemiology Laboratory for their assistance with recruitment and biospecimen processing, and Dr. John Lai, XiaoQing Chen and Dr. Jonathan Beesley for advice.

Funding was provided by the National Health and Medical Research Council [Early Career Fellowships (JB and MGL; 1035721), Career Development Award (SKC), Senior Research Fellowship (ABS), Principal Research Fellowship (JAC), Project Grant (no. 1009458) and Enabling Grant (APCB; no. 614296)], the Prostate Cancer Foundation of Australia [Movember Young Investigator Grant (MGL), Project Grant (PG7) and research infrastructure grant (APCB)], The Cancer Council Queensland, Prostate Cancer Research Program (SKC), QLD Government Smart State award (TOM), Australian Postgraduate Award (TOM) and the Institute of Health and Biomedical Innovation (JB, TOM).

\section{References}

Adzhubei, I.A., Schmidt, S., Peshkin, L., Ramensky, V.E., Gerasimova, A., Bork, P., Kondrashov, A.S., and Sunyaev, S.R. (2010). A method and server for predicting damaging missense mutations. Nat. Methods. 7, 248-249.

Akamatsu, S., Takata, R., Ashikawa, K., Hosono, N., Kamatani, N., Fujioka, T., Ogawa, O., Kubo, M., Nakamura, Y., and Nakagawa, H. (2010). A functional variant in NKX3.1 associated with prostate cancer susceptibility down-regulates NKX3.1 expression. Hum. Mol. Genet. 19, 4265-4272.

Amigo, J., Salas, A., Phillips, C., and Carracedo, A. (2008). SPSmart: adapting population based SNP genotype databases for fast and comprehensive web access. BMC Bioinformatics 9, 428.

Baade, P.D., Aitken, J.F., Ferguson, M., Gardiner, R.A., and Chambers, S.K. (2010). Diagnostic and treatment pathways for men with prostate cancer in Queensland: investigating spatial and demographic inequalities. BMC Cancer 10, 452.

Barrett, J.C., Fry, B., Maller, J., and Daly, M.J. (2005). Haploview: analysis and visualization of $\mathrm{LD}$ and haplotype maps. Bioinformatics 21, 263-265.

Bendtsen, J.D., Nielsen, H., Von Heijne, G., and Brunak, S. (2004). Improved prediction of signal peptides: SignalP 3.0. J. Mol. Biol. 340, 783-795.

Bolton, E.C., So, A.Y., Chaivorapol, C., Haqq, C.M., Li, H., and Yamamoto, K.R. (2007). Cell- and gene-specific regulation of primary target genes by the androgen receptor. Genes Dev. 21, 2005-2017.

Borgono, C.A., Grass, L., Soosaipillai, A., Yousef, G.M., Petraki, C.D., Howarth, D.H., Fracchioli, S., Katsaros, D., and Diamandis, E.P. (2003). Human kallikrein 14: a new potential biomarker for ovarian and breast cancer. Cancer Res. 63, 9032-9041.

Borgono, C.A., Michael, I.P., Shaw, J.L., Luo, L.Y., Ghosh, M.C., Soosaipillai, A., Grass, L., Katsaros, D., and Diamandis, E.P. (2007). Expression and functional characterization of the cancer-related serine protease, human tissue kallikrein 14. J. Biol. Chem. 282, 2405-2422.

Brattsand, M., Stefansson, K., Lundh, C., Haasum, Y., and Egelrud, T. (2005). A proteolytic cascade of kallikreins in the stratum corneum. J. Invest. Dermatol. 124, 198-203.

Brown, M.B. and Forsythe, A.B. (1974). Robust tests for equality of variances. J. Am. Stat. Assoc. 69, 364-367.

Clegg, N., Eroglu, B., Ferguson, C., Arnold, H., Moorman, A., and Nelson, P.S. (2002). Digital expression profiles of the prostate androgen-response program. J. Steroid. Biochem. Mol. Biol. 80, $13-23$.

Clements, J.A., Willemsen, N.M., Myers, S.A., and Dong, Y. (2004). The tissue kallikrein family of serine proteases: functional roles in human disease and potential as clinical biomarkers. Crit. Rev. Clin. Lab. Sci. 41, 265-312.

Duggan, D., Zheng, S.L., Knowlton, M., Benitez, D., Dimitrov, L., Wiklund, F., Robbins, C., Isaacs, S.D., Cheng, Y., Li, G., et al. (2007). Two genome-wide association studies of aggressive prostate cancer implicate putative prostate tumor suppressor gene DAB2IP. J. Natl. Cancer Inst. 99, 1836-1844.

Eeles, R.A., Kote-Jarai, Z., Giles, G.G., Olama, A.A., Guy, M., Jugurnauth, S.K., Mulholland, S., Leongamornlert, D.A., Edwards, S.M., Morrison, J., et al. (2008). Multiple newly 
identified loci associated with prostate cancer susceptibility. Nat Genet. 40, 316-321.

Eeles, R.A., Kote-Jarai, Z., Al Olama, A.A., Giles, G.G., Guy, M., Severi, G., Muir, K., Hopper, J.L., Henderson, B.E., Haiman, C.A., et al. (2009). Identification of seven new prostate cancer susceptibility loci through a genome-wide association study. Nat. Genet. 41, 1116-1121.

Emami, N. and Diamandis, E.P. (2008). Human kallikrein-related peptidase 14 (KLK14) is a new activator component of the KLK proteolytic cascade. Possible function in seminal plasma and skin. J. Biol. Chem. 283, 3031-3041.

Emami, N. and Diamandis, E.P. (2010). Potential role of multiple members of the kallikrein-related peptidase family of serine proteases in activating latent TGF $\beta 1$ in semen. Biol. Chem. 391, 85-95.

Emami, N., Deperthes, D., Malm, J., and Diamandis, E.P. (2008). Major role of human KLK14 in seminal clot liquefaction. J. Biol. Chem. 283, 19561-19569.

Fitzgerald, L.M., Kwon, E.M., Conomos, M.P., Kolb, S., Holt, S.K., Levine, D., Feng, Z., Ostrander, E.A., and Stanford, J.L. (2011). Genome-wide association study identifies a genetic variant associated with risk for more aggressive prostate cancer. Cancer Epidemiol. Biomarkers Prev. 20, 1196-1203.

Goard, C.A., Bromberg, I.L., Elliott, M.B., and Diamandis, E.P. (2007). A consolidated catalogue and graphical annotation of dbSNP polymorphisms in the human tissue kallikrein (KLK) locus. Mol. Oncol. 1, 303-312.

Grabe, N. 2000. AliBaba2.1 [Online]. Available: www.gene-regulation.com/pub/programs/alibaba2/index.html [Accessed August 2011].

Gratio, V., Loriot, C., Virca, G.D., Oikonomopoulou, K., Walker, F., Diamandis, E.P., Hollenberg, M.D., and Darmoul, D. (2011). Kallikrein-related peptidase 14 acts on proteinase-activated receptor 2 to induce signaling pathway in colon cancer cells. Am. J. Pathol. 179, 2625-2636.

Grosse, A., Bartsch, S., and Baniahmad, A. (2012). Androgen receptor-mediated gene repression. Mol. Cell Endocrinol. 352, 46-56.

Hodgson, M.C., Astapova, I., Hollenberg, A.N., and Balk, S.P. (2007). Activity of androgen receptor antagonist bicalutamide in prostate cancer cells is independent of NCoR and SMRT corepressors. Cancer Res. 67, 8388-8395.

Holzbeierlein, J., Lal, P., Latulippe, E., Smith, A., Satagopan, J., Zhang, L., Ryan, C., Smith, S., Scher, H., Scardino, P., et al. (2004). Gene expression analysis of human prostate carcinoma during hormonal therapy identifies androgen-responsive genes and mechanisms of therapy resistance. Am. J. Pathol. 164, 217-227.

Hooper, J.D., Bui, L.T., Rae, F.K., Harvey, T.J., Myers, S.A., Ashworth, L.K., and Clements, J.A. (2001). Identification and characterization of KLK14, a novel kallikrein serine protease gene located on human chromosome 19q13.4 and expressed in prostate and skeletal muscle. Genomics 73, 117-122.

Jia, L., Shen, H.C., Wantroba, M., Khalid, O., Liang, G., Wang, Q., Gentzschein, E., Pinski, J.K., Stanczyk, F.Z., Jones, P.A., et al. (2006). Locus-wide chromatin remodeling and enhanced androgen receptor-mediated transcription in recurrent prostate tumor cells. Mol. Cell. Biol. 26, 7331-7341.

Jia, L., Berman, B.P., Jariwala, U., Yan, X., Cogan, J.P., Walters, A., Chen, T., Buchanan, G., Frenkel, B., and Coetzee, G.A. (2008). Genomic androgen receptor-occupied regions with different functions, defined by histone acetylation, coregulators and transcriptional capacity. PLoS ONE 3, e3645.
Johnson, A.D., Handsaker, R.E., Pulit, S.L., Nizzari, M.M., O'Donnell, C.J., and De Bakker, P.I. (2008). SNAP: a webbased tool for identification and annotation of proxy SNPs using HapMap. Bioinformatics 24, 2938-2939.

Kader, A.K., Sun, J., Isaacs, S.D., Wiley, K.E., Yan, G., Kim, S.T., Fedor, H., Demarzo, A.M., Epstein, J.I., Walsh, P.C., et al. (2009). Individual and cumulative effect of prostate cancer riskassociated variants on clinicopathologic variables in 5,895 prostate cancer patients. Prostate 69, 1195-1205.

Kennedy, B.A., Gao, W., Huang, T.H., and Jin, V.X. (2010). HRTBLDb: an informative data resource for hormone receptors target binding loci. Nucleic Acids Res. 38, D676-681.

Klein, R.J., Hallden, C., Cronin, A.M., Ploner, A., Wiklund, F., Bjartell, A.S., Stattin, P., Xu, J., Scardino, P.T., Offit, K., et al. (2010). Blood biomarker levels to aid discovery of cancer-related single-nucleotide polymorphisms: kallikreins and prostate cancer. Cancer Prev. Res. (Phila.) 3, 611-619.

Kojima, S., Mulholland, D.J., Ettinger, S., Fazli, L., Nelson, C.C., and Gleave, M.E. (2006). Differential regulation of IGFBP-3 by the androgen receptor in the lineage-related androgen-dependent LNCaP and androgen-independent $\mathrm{C} 4-2$ prostate cancer models. Prostate 66, 971-986.

Kote-Jarai, Z., Amin Al Olama, A., Leongamornlert, D., Tymrakiewicz, M., Saunders, E., Guy, M., Giles, G.G., Severi, G., Southey, M., Hopper, J.L., et al. (2011). Identification of a novel prostate cancer susceptibility variant in the KLK3 gene transcript. Hum. Genet. 129, 687-694.

Lai, J., Kedda, M.A., Hinze, K., Smith, R.L., Yaxley, J., Spurdle, A.B., Morris, C.P., Harris, J., and Clements, J.A. (2007). PSA/KLK3 AREI promoter polymorphism alters androgen receptor binding and is associated with prostate cancer susceptibility. Carcinogenesis 28, 1032-1039.

Lawrence, M.G., Lai, J., and Clements, J.A. (2010). Kallikreins on steroids: structure, function, and hormonal regulation of prostatespecific antigen and the extended kallikrein locus. Endocr. Rev. 31, 407-446.

Lin, D.W., Fitzgerald, L.M., Fu, R., Kwon, E.M., Zheng, S.L., Kolb, S., Wiklund, F., Stattin, P., Isaacs, W.B., Xu, J., et al. (2011). Genetic variants in the LEPR, CRY1, RNASEL, IL4, and ARVCF genes are prognostic markers of prostate cancerspecific mortality. Cancer Epidemiol. Biomarkers Prev. 20, 1928-1936.

Lose, F., Nagle, C.M., O'mara, T., Batra, J., Bolton, K.L., Song, H., Ramus, S.J., Gentry-Maharaj, A., Menon, U., Gayther, S.A., et al. (2010). Vascular endothelial growth factor gene polymorphisms and ovarian cancer survival. Gynecol. Oncol. 119, 479-483.

Lose, F., Batra, J., O’mara, T., Fahey, P., Marquart, L., Eeles, R.A., Easton, D.F., Al Olama, A.A., Kote-Jarai, Z., Guy, M., et al. (2011). Common variation in kallikrein genes KLK5, KLK6, KLK12, and KLK13 and risk of prostate cancer and tumor aggressiveness. Urol Oncol.

Lubahn, J., Berndt, S.I., Jin, C.H., Klim, A., Luly, J., Wu, W.S., Isaacs, S., Wiley, K., Isaacs, W.B., Suarez, B.K., et al. (2010). Association of CASP8 D302H polymorphism with reduced risk of aggressive prostate carcinoma. Prostate 70, 646-653.

Mavridis, K. and Scorilas, A. (2010). Prognostic value and biological role of the kallikrein-related peptidases in human malignancies. Future Oncol. 6, 269-285.

Mostaghel, E.A., Page, S.T., Lin, D.W., Fazli, L., Coleman, I.M., True, L.D., Knudsen, B., Hess, D.L., Nelson, C.C., Matsumoto, A.M., et al. (2007). Intraprostatic androgens and androgen-regulated gene expression persist after testosterone suppression: 
therapeutic implications for castration-resistant prostate cancer. Cancer Res. 67, 5033-5041.

Nakai, K. and Horton, P. (1999). PSORT: a program for detecting sorting signals in proteins and predicting their subcellular localization. Trends Biochem. Sci. 24, 34-36.

Ng, P.C. and Henikoff, S. (2001). Predicting deleterious amino acid substitutions. Genome Res. 11, 863-874.

Oikonomopoulou, K., Hansen, K.K., Saifeddine, M., Vergnolle, N., Tea, I., Blaber, M., Blaber, S.I., Scarisbrick, I., Diamandis, E.P., and Hollenberg, M.D. (2006). Kallikrein-mediated cell signalling: targeting proteinase-activated receptors (PARs). Biol. Chem. 387, 817-824.

Oon, S.F., Pennington, S.R., Fitzpatrick, J.M., and Watson, R.W. (2011). Biomarker research in prostate cancer - towards utility, not futility. Nat. Rev. Urol. 8, 131-138.

Paliouras, M. and Diamandis, E.P. (2007). Coordinated steroid hormone-dependent and independent expression of multiple kallikreins in breast cancer cell lines. Breast Cancer Res. Treat. 102, 7-18.

Paliouras, M. and Diamandis, E.P. (2008a). Androgens act synergistically to enhance estrogen-induced upregulation of human tissue kallikreins 10,11, and 14 in breast cancer cells via a membrane bound androgen receptor. Mol. Oncol. 1, 413-424.

Paliouras, M. and Diamandis, E.P. (2008b). Intracellular signaling pathways regulate hormone-dependent kallikrein gene expression. Tumour Biol. 29, 63-75.

Parikh, H., Wang, Z., Pettigrew, K.A., Jia, J., Daugherty, S., Yeager, M., Jacobs, K.B., Hutchinson, A., Burdett, L., Cullen, M., et al. (2011). Fine mapping the KLK3 locus on chromosome 19q13.33 associated with prostate cancer susceptibility and PSA levels. Hum. Genet. 129, 675-685.

Prescott, J., Jariwala, U., Jia, L., Cogan, J.P., Barski, A., Pregizer, S., Shen, H.C., Arasheben, A., Neilson, J.J., Frenkel, B., et al. (2007). Androgen receptor-mediated repression of novel target genes. Prostate 67, 1371-1383.

Rabien, A., Fritzsche, F., Jung, M., Diamandis, E.P., Loening, S.A., Dietel, M., Jung, K., Stephan, C., and Kristiansen, G. (2008). High expression of KLK14 in prostatic adenocarcinoma is associated with elevated risk of prostate-specific antigen relapse. Tumour Biol. 29, 1-8.

Rajapakse, S. and Takahashi, T. (2007). Expression and enzymatic characterization of recombinant human kallikrein 14. Zool. Sci. 24, 774-780.

Riva, A. and Kohane, I.S. (2004). A SNP-centric database for the investigation of the human genome. BMC Bioinformatics 5,33 .

Sandelin, A. and Wasserman, W.W. (2005). Prediction of nuclear hormone receptor response elements. Mol. Endocrinol. 19, 595-606.

Sankpal, U.T., Goodison, S., Abdelrahim, M., and Basha, R. (2011). Targeting sp1 transcription factors in prostate cancer therapy. Med. Chem. 7, 518-525.
Shaw, J.L. and Diamandis, E.P. (2008). Regulation of human tissue kallikrein-related peptidase expression by steroid hormones in 32 cell lines. Biol. Chem. 389, 1409-1419.

Sherry, S.T., Ward, M.H., Kholodov, M., Baker, J., Phan, L., Smigielski, E.M., and Sirotkin, K. (2001). dbSNP: the NCBI database of genetic variation. Nucleic Acids Res. 29, 308-311.

Smith, P.J., Zhang, C., Wang, J., Chew, S.L., Zhang, M.Q., and Krainer, A.R. (2006). An increased specificity score matrix for the prediction of SF2/ASF-specific exonic splicing enhancers. Hum. Mol. Genet. 15, 2490-2508.

Stefansson, K., Brattsand, M., Roosterman, D., Kempkes, C., Bocheva, G., Steinhoff, M., and Egelrud, T. (2008). Activation of proteinase-activated receptor- 2 by human kallikrein-related peptidases. J. Invest. Dermatol. 128, 18-25.

Thompson, V.C., Morris, T.G., Cochrane, D.R., Cavanagh, J., Wafa, L.A., Hamilton, T., Wang, S., Fazli, L., Gleave, M.E., and Nelson, C.C. (2006). Relaxin becomes upregulated during prostate cancer progression to androgen independence and is negatively regulated by androgens. Prostate 66, 1698-1709.

Veveris-Lowe, T.L., Kruger, S.J., Walsh, T., Gardiner, R.A., and Clements, J.A. (2007). Seminal fluid characterization for male fertility and prostate cancer: kallikrein-related serine proteases and whole proteome approaches. Semin. Thromb. Hemost. 33, 87-99.

Witte, J.S. (2009). Prostate cancer genomics: towards a new understanding. Nat. Rev. Genet. 10, 77-82.

Yeager, M., Orr, N., Hayes, R.B., Jacobs, K.B., Kraft, P., Wacholder, S., Minichiello, M.J., Fearnhead, P., Yu, K., Chatterjee, N., et al. (2007). Genome-wide association study of prostate cancer identifies a second risk locus at 8q24. Nat. Genet. 39, 645-649.

Yoon, H., Laxmikanthan, G., Lee, J., Blaber, S.I., Rodriguez, A., Kogot, J.M., Scarisbrick, I.A., and Blaber, M. (2007). Activation profiles and regulatory cascades of the human kallikrein-related peptidases. J. Biol. Chem. 282, 31852-31864.

Yousef, G.M., Magklara, A., Chang, A., Jung, K., Katsaros, D., and Diamandis, E.P. (2001). Cloning of a new member of the human kallikrein gene family, KLK14, which is down-regulated in different malignancies. Cancer Res. 61, 3425-3431.

Yousef, G.M., Fracchioli, S., Scorilas, A., Borgono, C.A., Iskander, L., Puopolo, M., Massobrio, M., Diamandis, E.P., and Katsaros, D. (2003a). Steroid hormone regulation and prognostic value of the human kallikrein gene 14 in ovarian cancer. Am. J. Clin. Pathol. 119, 346-355.

Yousef, G.M., Stephan, C., Scorilas, A., Ellatif, M.A., Jung, K., Kristiansen, G., Jung, M., Polymeris, M.E., and Diamandis, E.P. (2003b). Differential expression of the human kallikrein gene 14 (KLK14) in normal and cancerous prostatic tissues. Prostate 56, 287-292.

Received November 18, 2011; accepted March 13, 2012 